\title{
La Ocupación y Pre Ocupación desde una dimensión temporal
}

MONTENEGRO MEDINA, MARIA ANGELICA

\section{- Resumen}

Se analizan la ocupación y la preocupación desde una dimensión temporal. Se abordan algunos conceptos en torno a la vivencia del tiempo y se establece un correlato con algunas etapas del ciclo evolutivo.

Se analiza el rol del Terapeuta Ocupacional a la luz de estos conceptos y algunos cuadros psicopatológicos más frecuentes.

\begin{abstract}
- Abstract
Occupation and preoccupation was analyzed from a temporal dimension. Some concepts about time experience and their correlation with vital cycle were developed. Occupational Therapy role and some common psychopathological disorders are reviewed.
\end{abstract}




\section{- Introducción "}

Pareciera ser que tanto desde una perspectiva ontogénica como filogenética, el trabajo da señales de un temprana aparición.

Una posición antropológica, probablemente hará mayor énfasis, en que esta actividad consustantiva de lo humano es la que le otorga su impronta o sello personal. Una mirada sociológica en cambio considerará aspectos relacionales del quehacer en las distintas etapas históricas. Así la concepción del trabajo ha variado desde su ejecución en condiciones infrahumanas en la Roma Antigua, hasta la Revolución Industrial con el consecuente surgimiento del capitalismo que obligó a establecer nuevas órdenes sociales.

Hay quienes plantean sutiles disquisiciones terminológicas, en términos de señalar que TRABAJO sería un concepto biológico que representaría un esfuerzo individual dirigido al logro de un rendimiento; PROFESIÓN en cambio sería un concepto mas abstracto y determinado culturalmente y OCUPACIÓN en tanto se entendería como predominantemente económico y supone una actividad destinada a recibir un salario.

Dado que en nuestra reflexión queremos incluir la variable temporalidad, diremos que la ocupación o más bien la ejecución de una ocupación, exige necesariamente una inversión de tiempo. El sentimiento respecto de esta inversión puede ser placentero o displacentero según sea la naturaleza de la tarea desempeñada y las catexias depositadas en ella.

Al respecto, la vivencia de la temporalidad posee 2 claras dimensiones: el tiempo PATICO, aquel tiempo individual independiente del cronológico, aquel que se abrevia en condiciones de placer y que se extiende en condición de infortunio. Este desde luego es obviamente SUBJETIVO.

El tiempo GNÓSTICO en cambio, es aquel que da cuenta de la realidad objetiva, observable, cuantificable, medible. Su origen parece estar en el griego "gnomon", algo análogo a medida, escala, regla graduada, pero que en su sentido original daba cuenta del reloj de sol. Por otra parte representa el dialéctico encuentro del hombre con la naturaleza en torno a una medida. El hombre crea un disco y un puntero con el propósito de medir la rotación cósmica que no puede ser leída por cualquiera sino por un "conocedor", alguien que sabe leer el tiempo y comprender su perfecta regularidad ${ }^{(1)}$.

En el proyecto vital, el tiempo es vivido siempre como un continuo; se está permanentemente entre el "ya no" y el "todavía no".

A la persona en tanto, le es característico existir en la ejecutividad de sus actos ${ }^{(2)}$.

Cada uno de esos actos o de sus modos de actividad dice relación con un por qué final, que a la postre conduce a una cierta autorrealización.

En la ocupación pragmática por llamarla de algún modo, el por qué final puede ser un producto tangible, observable; en la ocupación cognitiva en tanto el producto puede ser bienestar, satisfacción, mayor caudal de conocimientos etc. Al respecto, la ocupación en tanto ACTO, implica grados de libertad y pone en el escenario de manera importante la voluntad.

Autores como López Ibor establecen una clara diferencia entre voluntad y gana, estando la primera orientada siempre al cumplimiento de un determinado fin. La gana en tanto parece ser un estilo de voluntad primordial, un deseo que emerge sin reflexión, situándose entonces fuera de los dominios de la conciencia. 
Durante el ciclo vital, la elección de la profesión u oficio que se ejecutará a lo largo de la vida, debe hacerse en una de las etapas de más alta vulnerabilidad: la adolescencia. Del latín ADOLESCERE = PADECER, se entiende como una edad donde emergen intensos cuestionamientos de gran diversidad. Precisamente allí tiene ocurrencia este megaevento: la opción libre y voluntaria respecto de en qué, se estará ocupado los 50 años o más que dura la vida una vez finalizada la adolescencia.

El hombre normal vive en permanente PROYECTO con su consecuente dimensión temporal:

PROYECTO $\rightarrow$ TRASCENDER $\rightarrow$ FUTURO

Desde una perspectiva existencial, el futuro del hombre es siempre aciago, incierto, de la único que se tiene certeza absoluta es de la muerte, de la finitud. Pese a lo anterior, el hombre se proyecta realizando saltos temporales en los que se convoca a sí mismo y no pocas veces a otros a un encuentro, sin tener la certidumbre de poder asistir a tal convocatoria.

En este sentido, sí bien el futuro representa esperanza y perspectiva, esta no fluye ampliamente. Hidegger supone en el concepto de futuro, temor y prisión ante el límite inapelable de la existencia: la muerte.

En el proyecto vital, el tiempo es vivido siempre como un continuo; se está permanentemente entre el "ya no" y el "todavía no".

\section{- El rol del Terapeuta Ocupacional desde la perspectiva de la ocupación "}

Tal vez uno de los dilemas de la Edad Adulta que se debe resolver con mayor propiedad y sensación de logro, es el de generatividad vs estancamiento. Al respecto Erickson formula que en la etapa media de la vida, el sujeto se plantea TRASCENDER a través de aquello que eventualmente pueda perpetuar en las futuras generaciones. Así algunos privilegian dejar a los suyos un patrimonio material que proporcione un cierto sustento, en tanto otros optan por legados tales como formación valórica y/o entrega de conocimientos.

De las tantas tipologías de rol, suscribiremos la de rol adscrito y rol adquirido. Las características del rol adscrito son todas aquellas condiciones que nos son otorgadas naturalmente: sexo, nacionalidad, pertenencia a una determinada familia. Por su parte el rol adquirido lo constituye todo aquello que es asumido con activa intervención de la propia voluntad: la profesión u oficio, el estado civil, la elección de amigos etc.

Así las cosas, el Terapeuta Ocupacional, opta en su etapa de máxima fragilidad y en un acto de máxima libertad "ocuparse" a lo largo de su biografía (bio = vida; graphos= trazado o escritura), del cabal restablecimiento de otros. Se ocupa de ellos para que a su vez ellos, puedan volver a ocuparse en lo suyo.

La praxis del cuidado parece ser inherente a la condición humana. Si no todos optan por ocupaciones de servicio o de bienestar social, ¿qué hace que en su definición el Terapeuta Ocupacional se ocupe de manera tal que su paciente también se re-ocupe?.

Desde la perspectiva de la Psicología Evolutiva, un intento explicativo sería que el Terapeuta Ocupacional resuelva su dilema generatividad vs. estancamiento a través de generar restablecimiento, rehabilitación, reinserción de otros. 
Enrique Rojas señala que el hombre es lo que es y lo que ama. La ejecutividad y los afectos. En una dolencia de carácter físico y/o psicológico indudablemente se resiente el carácter vincular de las relaciones. El Terapeuta Ocupacional intentará recuperar su funcionalidad cualquiera que sea, de forma que en lo posible al retomar su ocupación el sujeto se legitime en su identidad. ${ }^{(4)}$

\section{- La preocupación y su carácter temporal "}

Como ya señaláramos la ocupación ejecutada con placer e interés es conducente a diversos grados de autorealización.

En la pre-ocupación sin embargo, hay una inversión de tiempo habitualmente displacentera y conducente a nada. El sujeto se anticipa a la eventual ocurrencia de algo cuyo sustrato fundamental parece ser la ansiedad.

El problema de la pre-ocupación a diferencia de la ocupación es que inhabilita, no hay acto, hay ausencia de ejecutividad.

El des-ocupado (cesante) ocupado, realizará múltiples acciones tendientes todas a la consecución de un logro: la obtención de un puesto. El des-ocupado, solo pre-ocupado es probable que divague y que finalmente se quede en la nada.

En la ocupación el sujeto suele tener el control; en la pre-ocupación se pierde el control respecto de los propios actos.

\section{- Desde la mirada de la ocupación y la pre-ocupación, algunos cuadros psicopatológicos :}

Una de las metas que debe alcanzarse durante la adolescencia es la formulación de un plan de vida. Esto desde luego, solo puede tener ocurrencia en el sujeto normal y en condición de óptima salud mental. La Esquizofrenia a su vez, una de las enfermedades más devastadoras del espectro de la Psiquiatría, suele debutar en esta etapa de la vida, siendo el desgano, el autismo y particularmente la APROPOSITIVIDAD VITAL, los síntomas que a la postre, impedirán la formulación de un proyecto de vida, que finalmente es lo que otorga coherencia al sujeto.

El enfermo esquizofrénico se convertirá entonces casi de por vida en un sujeto desocupado. No es menos cierto, que la psicofarmacología actual ha contribuido importantemente en el tratamiento de los síntomas esquizofrénicos; no obstante los síntomas positivos son los que aparentemente responden, antes y mejor a los neurolépticos de última generación.

Por su parte en los Trastornos de Ansiedad lo que suele prevalecer es la preocupación, que en psicopatología suele llamársele expectación ansiosa o ansiedad anticipatoria por un evento que aún no ha tenido ocurrencia; a exponerse frente a un público, a las multitudes, a los espacios abiertos, etc.

Algunos teóricos ${ }^{(3)}$ señalan que la imaginación si bien no existe como acto o ejecución concreta, si existe como función simbólica en el espacio intrapsíquico. Dependiendo de la fuerza y de la "concretud" de esa imagen puede llegar a inhabilitar totalmente al sujeto. Conocidas son por el lego las diversas formas de zoofobia. 
En la fase maníaca en tanto, al igual que en el Trastorno Obsesivo - Compulsivo lo que parece estar a la base es una ocupación excesiva.

En la manía, la exaltación del ánimo y la alteración de los ritmos biológicos, particularmente el ciclo sueño - vigilia parecen comandar la hiperactividad o si se le quiere llamar la sobreocupación.

En el Trastorno Obsesivo Compulsivo, el sujeto suele estar ocupado o también sobreocupado en múltiples tareas compulsivas y totalmente inútiles o inoficiosas: lavarse repetidamente las manos 0 limpiar incesantemente utensilios, revisar recurrentemente llaves o cerraduras sin llegar a tener nunca la sensación de tarea cumplida. Si bien el enfermo que padece este trastorno lucha activamente con sus obsesiones y presenta una importante carga de ansiedad, no puede evitarlo.

\section{- Discusión "}

El hombre es un ser eminentemente temporal, orientado en una única dirección irreversible: la muerte. En su trayecto alcanzará diversos grados de autorrealización dependiendo de la calidad de sus actuaciones, en tanto actos de vida en las áreas personal, relacional, familiar y social.

La condición temporal es lo que constituye la historicidad del hombre, que se entiende como existencia en tanto extensión, abarcando su propio comienzo y simultáneamente su propio fin.

En esta extensión será pertinente la elaboración de un plan de vida asociado a un concepto integrado y coherente de sí mismo y del medio, que desde luego se reformula permanentemente a lo largo de la vida según sucesivas confrontaciones con la realidad interna y externa.

Este planteamiento que se realiza con cierta placidez cuando hay salud, obviamente se ve interrumpido en condición de enfermedad, siendo tal vez los padecimientos psiquiátricos, los más devastadores y marginales en este aspecto.

En este análisis, hemos intentado revisar los conceptos de ocupación, preocupación y desocupación. A la luz de éstos, hemos hecho alguna reflexión, en torno a algunos trastornos psiquiátricos de mayor frecuencia diagnóstica en la práctica clínica. Aunque nuestro esfuerzo fue exhaustivo, tenemos certeza que el tema exige mayor observación empírica, de manera que la sola variable OCUPACIÓN, permita una orientación diagnóstica de la máxima precisión. 
- Referencias

(1) HEERLEIN A. Personalidad y Psicopatología Ediciones de la Sociedad de Neurología, Neuropsiquiatría y Psiquiatría.

(2) MASLOW A. La Personalidad Creadora, 2da. Edición, 1985, Kairós, Barcelona, España.

(3) CHAUCHARD P. El cerebro y la mano creadora, NARCEA S.A. EDICIONES. 1972, Madrid, España.

(4) ROJAS ENRIQUE, Una teoría de la felicidad, 4a Edición, Editorial Dossat S.A. Madrid 1987. 